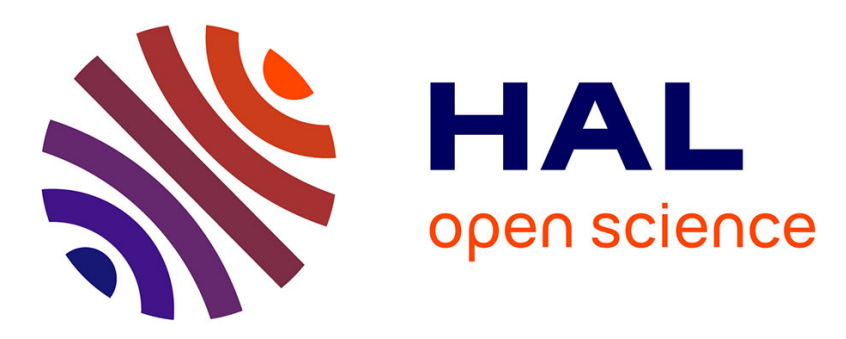

\title{
Finite element modelling of non-faradic electric impedance spectroscopy through flexible polymer microchip
}

Mohammed Kechadi, Lila Chaal, Vincent Vivier, Bernard Tribollet, Jean Gamby

\section{To cite this version:}

Mohammed Kechadi, Lila Chaal, Vincent Vivier, Bernard Tribollet, Jean Gamby. Finite element modelling of non-faradic electric impedance spectroscopy through flexible polymer microchip. Journal of Electroanalytical Chemistry, 2017, 807, pp.203-212. 10.1016/j.jelechem.2017.11.022 . hal-01643593

\section{HAL Id: hal-01643593 https://hal.sorbonne-universite.fr/hal-01643593}

Submitted on 23 Nov 2017

HAL is a multi-disciplinary open access archive for the deposit and dissemination of scientific research documents, whether they are published or not. The documents may come from teaching and research institutions in France or abroad, or from public or private research centers.
L'archive ouverte pluridisciplinaire HAL, est destinée au dépôt et à la diffusion de documents scientifiques de niveau recherche, publiés ou non, émanant des établissements d'enseignement et de recherche français ou étrangers, des laboratoires publics ou privés. 


\title{
Finite element modelling of non-faradic electric impedance spectroscopy through flexible polymer microchip
}

\author{
Mohammed Kechadi, ${ }^{\mathrm{a}, \mathrm{b}}$ Lila Chaal, ${ }^{\mathrm{b}}$ Vincent Vivier, ${ }^{\mathrm{a}}$ Bernard Tribollet, ${ }^{\mathrm{a}}$ and Jean Gamby ${ }^{\mathrm{a}, \mathrm{c}, *}$
}

a. Sorbonne Universités, UPMC Univ Paris 06, CNRS, Laboratoire Interfaces et Systèmes Electrochimiques, 4 place Jussieu, F-75005, Paris, France.

b. Laboratoire d'Electrochimie, Corrosion et de Valorisation Energétique (LECVE), Faculté de Technologie, Université de Bejaia (06000), Algérie.

c. Centre de Nanosciences et de Nanotechnologies, CNRS, Univ. Paris-Sud, Université Paris-Saclay, C2N - Marcoussis, 91460 Marcoussis, France.

* E-mail address: jean.gamby@c2n.upsaclay.fr (J. Gamby)

Centre de Nanosciences et de Nanotechnologies, CNRS, Univ. Paris-Sud, Université Paris-Saclay, C2N Marcoussis, 91460 Marcoussis, France. Corresponding author. Tel: +331696360 60; fax: +33169636006.

\begin{abstract}
Numerical simulations using finite element method were performed for a better understanding of nonfaradic electric impedance response of microfluidic device with two insulated planar-microband electrodes i.e. electrodes without direct contact with electrolyte flowing in the microchannel. The results showed that calculated electric impedance depends not only on the microchannel geometry and dielectric properties of electrolyte flowing in microchannel, but also on the dielectric response of the insulated PET layer. It was pointed out that a microfluidic device with insulated microelectrodes behaves as a dielectric device, in which a strong capacitive coupling effect takes place in the high-frequency domain. An analytical expression that allows predicting the optimal frequency range to be used for measuring real-time contactless microchannel resistance changes was proposed. This non-faradic impedance spectroscopy appears to be a promising approach for the new generation of sensors and biosensors in miniaturized flexible or patch polymer devices.
\end{abstract}

Keywords: Microchannel, flexible polymer, non-faradic impedance, contactless, finite element method. 


\section{Introduction}

In the recent years, progresses in micro and nanofabrication techniques enabled a better control of the positioning of microscale electrodes and especially of the thickness of the insulating layer that can be deposited on them. These technical innovations in microelectrode network design and fabrication allowed new insights in contactless application fields such as scanning conductivity,[1],[2] dielectrophoresis actuation,[3],[4],[5],[6] microfluidic pumps,[7],[8] droplets generator,[9] particle sorting [10],[11] and biosensors. [12],[13], [14],[15],[16],[17] Furthermore, an important research topic in the last decade is the development of flexible polymer microdevices for bioanalytical applications integrating electrodes for biodetection.[18],[19],[20] For instance, a configuration of flexible microfluidic chips bearing contactless carbon microelectrodes was designed by using laser photoablation process in an insulated dielectric polymer as polyethylene terephthalate (PET). Additionally, an improvement of the measurement protocol and a better understanding of the impedance signal acquisition have permitted to apply a much lower AC voltage excitation amplitude (c.a. $100 \mathrm{mV}$ ) close to the range used in the conventional electrochemical impedance spectroscopy (EIS).[21] Although for contactless mode no faradic reaction was involved, a new generation of microchips for non-faradic electric impedance spectroscopy measurements appeared. It has been validated for two main applications based on the monitoring of specific biomolecular interactions between ligands in a microscale channel with an efficient and specific detection in a low volume chamber (300 pL).[22] This method could be used for real time monitoring of microchannel dielectric property changes i.e. its interfacial impedance in the low frequencies (LF) and resistance variations in the high frequencies (HF), while a chemical reaction was taking place at the functionalized PET surface (adsorption monitoring) [23],[24] or in the microchannel bulk (conductimetry),[15],[25], respectively. For instance, the interfacial capacitance changes during binding events (between two proteic ligands) were reported for the detection and quantification of a protein attached on PET by using its corresponding rabbit antiprotein antibodies as an analyte in the flow microchannel. This approach was also applied to record microchannel conductance variations in the small chamber with contactless electrodes in a PET microchannel. For instance, it was demonstrated that magnetic actuation could be used to move and immobilize alkaline phosphatase linked superparamagnetic microbeads as enzyme support in the detection chamber. When an enzyme-substrate in the mobile phase (monoesterphosphate) comes in contact with the enzyme biocatalytic center, the dephosphorylation reaction starts and the inorganic phosphate ions produced lead to an increase of the conductivity.[22],[15],[25] In this application, the great advantage of the mutual use of contactless microelectrodes and specific ligand linked to microbeads is to prevent microelectrodes fouling. Indeed, it is difficult to regenerate microelectrode surfaces in small channels. Here, the multiple use of the same PET microchip is possible, which also results in a lower risk of biological sample damage due to an enzyme activity lost.[25].

The promising non-faradic results obtained with this kind of flexible micro-device makes it a competitive biosensor. The objective of this paper is to gain in a better understanding of non-faradic principle through two planar microband electrodes embedded in a dielectric polymer. A specific attention will be paid to the use of finite element method for the calculation of the electric impedances involved at different interfaces. Numerical 
simulations were confronted with data obtained using the conventional electrical equivalent circuits approach.[21] Furthermore, the methodology presented here has a great interest for the microfluidic domain where flexible devices are still evolving.

\section{Materials and methods}

\subsection{Geometry of the micro-device}

The microdevice consisted in a $100 \mu \mathrm{m}$ thick polyethylene microchip bearing two $100 \mu \mathrm{m}$ parallel carbon microelectrodes separated from $120 \mu \mathrm{m}$ (edge to edge), with a $5 \mu \mathrm{m}$ polyethylene terephthalate layer as insulating layer (Fig. 1). The excitation signal used was a $100 \mathrm{mV}$ peak to peak sinewave in the frequency domain from $1 \mathrm{MHz}$ to $1 \mathrm{~Hz}$.

As demonstrated in previous papers,[21],[26] the experimental impedance through the whole microdevice, $Z_{G}(\omega)$, can be described by a parallel combination of two impedances, as

$Z_{G}(\omega)=\frac{Z_{1}(\omega) \cdot Z_{2}(\omega)}{Z_{1}(\omega)+Z_{2}(\omega)}$

The impedance $Z_{2}(\omega)$ accounts for the current streamlines passing through the two microelectrodes separated by the PET layer thickness $\left(d_{2, \mathrm{PET}}=120 \mu \mathrm{m}\right)$, and the impedance $Z_{l}(\omega)$ is ascribed to the contribution of the two PET layers $\left(d_{1, \mathrm{PET}}=5 \mu \mathrm{m}\right)$ that isolate electrodes from the electrolyte (Fig. 1).

In practice, the impedances $Z_{2},(\omega)$ and $Z_{G}(\omega)$ were measured from independent experiments in which the microchannel was first empty (air) and then filled with the electrolyte, respectively. The impedance $Z_{1}(\omega)$ can be readily deduced from the experimental value of the impedance $Z_{\mathrm{G}}(\omega)$, by eliminating the experimental value of the impedance $Z_{2}(\omega)$ using Eq. (1).

Moreover, using the electrical equivalent circuit approach presented in Fig. 1, $Z_{1}(\omega)$ can be expressed as a series association of the impedance corresponding to the contributions of the $5 \mu \mathrm{m}-\mathrm{PET}$ layer, $\mathrm{Z}_{1,-\mathrm{PET}}$,

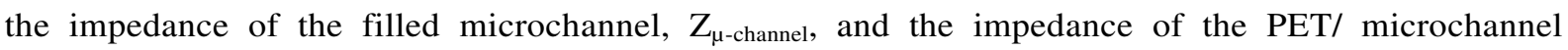
interface, $\mathrm{Z}_{\text {interface, }}$ as

$Z_{1}(\omega)=2 Z_{1, P E T}(\omega)+Z_{\mu-\text { channel }}(\omega)+2 Z_{\text {interface }}(\omega)$

In this expression, both interfaces formed by the microelectrode / PET / electrolyte are assumed to be identical.

Fig. 1

\subsection{Modelling procedure}

The physical model was derived by setting the mathematical equations of studied phenomenon (electrical, mechanical, etc.) represented in two-dimensions (2-D) or three-dimensions (3-D). The 
numerical resolution of the equations was performed using finite element method (Comsol Multiphysics package), with the electrical module. The geometry of whole device was split up into a set of different domains allowing different mesh sizes to be used on each domain depending on the initial geometry and the boundary conditions.

\section{Results and discussion}

\subsection{Electric field equations}

The modelling equation of the electric field $\vec{E}\left(\mathrm{~V} \cdot \mathrm{m}^{-1}\right)$ by using finite element requires resolution by putting in matrix form. As it is well known, the electric field applied in a dielectric medium is defined as a harmonic function as a function of time:

$E=E_{0} e^{i \omega t}$

where $\omega$ is the angular frequency, $\omega=\pi 2 f\left(\mathrm{rad} . \mathrm{s}^{-1}\right)$ and $f$ the frequency $(\mathrm{Hz})$. The current density can thus be expressed as:

$\vec{J}=\sigma_{S} \vec{E}+\varepsilon_{0} \varepsilon_{r} \frac{\partial \vec{E}}{\partial t}$

with $\varepsilon_{0}=8.85 \times 10^{-12}\left(\mathrm{~F} . \mathrm{m}^{-1}\right)$ the vacuum permittivity, $\varepsilon_{r}$ the relative permittivity of the medium, and $\sigma_{\mathrm{S}}$ $\left(\mathrm{S} . \mathrm{m}^{-1}\right)$ the static electrical conductivity.

The potential distribution inside the microchannel fulfilled the following relationships:

$\nabla\left(\left(\sigma_{s}+i \varepsilon_{0} \varepsilon_{r} \omega\right)(-\nabla V)\right)=0$

The resolution of the Eq. (5) using the finite elements method permits to represent the electrical field variation and the current density distribution in the spatial Cartesian coordinates $(\mathrm{x}, \mathrm{y}, \mathrm{z})$, and thus to calculate the electric impedance transfer function.

\subsection{Initial and boundary conditions}

In order to solve equation (5), we defined the physical properties for the different boundaries of the geometry sketched in Fig. 2. The physical properties to be set were the relative permittivity and the electrical conductivity, which may be either constant or frequency dependent values. The initial condition $(t=0)$ for the electrical field was defined as $V_{(\mathrm{t}=0)}=0$ and an electric potential condition $\left(V_{e l}=\right.$ $V)$ was defined and applied on each electrode surface. Theelectrical insulation condition $(n J=0)$ was used on the external borders of the geometry meaning that no electric current flows beyond the external borders of the geometry. 
The distributed impedance was defined according to Eq. 6 in a layer in which the electrical conductivity $\left(\sigma_{S}\right)$ of medium (or material), the relative permittivity $\left(\varepsilon_{r}\right)$ and the layer thickness $\left(d_{S}\right)$ can be specified.

$n .\left(J_{1}-J_{2}\right)=\frac{\left(\sigma_{S}+j \omega \varepsilon_{0} \varepsilon_{r}\right)}{d_{S}}\left(V-V_{r e f}\right)=\left(\frac{1}{\rho_{S}}+j \omega C_{\text {int }}\right)\left(V-V_{r e f}\right)$

where the subscripts 1 and 2 denote the two sides of the border, $V_{\text {ref }}$ is the electrode potential, $\rho_{S}$ the surface resistance $(\Omega . \mathrm{m})$, and $C_{i n t}$ is the interface capacitance $\left(\mathrm{F} . \mathrm{m}^{-2}\right)$.

As shown in Fig. 2, a contact impedance was used for modeling the internal contacts between two medias, where a thin layer of resistive material has an effect on the resistivity distribution. This can be expressed:

$n . J_{1}=\frac{\left(\sigma^{*}+j \omega \varepsilon_{0} \varepsilon_{r}\right)}{d_{S}}\left(V_{1}-V_{2}\right)=\frac{1}{\rho_{S}}\left(V_{1}-V_{2}\right)$

where $\sigma^{*}$ corresponds to the real part of the conductivity and $j \omega \varepsilon_{0} \varepsilon_{r}$ is the imaginary part.

The surface resistivity at the microelectrode / PET interface was taken into account in this model in agreement with the resistivity model (RD) previously developed for describing the impedance at the gold / PET macrodisks interface [27].

Here, the electric conductivity at the surface is taken equal to $\sigma^{*}=3 \times 10^{-11}\left(\mathrm{~S}_{\mathrm{m}} \mathrm{m}^{-1}\right)$ and the thickness $\mathrm{d}_{\mathrm{S}}$ is the PET thickness $\left(d_{\mathrm{PET}, 1}=5 \mu \mathrm{m}\right)$ along which the resistivity distribution occurs led to a thickness $d_{S}=5$ nm.

Fig. 2

The modelling of the dielectric response of non-contact microchip device was performed for various microchannel electrical conductivities. The relative permittivity in the PET microchannel filled with an electrolyte was assumed to be similar to the relative permittivity of water (i.e. $\varepsilon_{r, \text { microchannel }}=78$ ).

For the sodium chloride $(\mathrm{NaCl})$ salt diluted in twice-distilled water, the electrolyte conductivity was calculated according to:

$\sigma_{\text {microcanal }}\left(S . m^{-1}\right)=\left(\lambda_{\mathrm{Na}^{+}}+\lambda_{\mathrm{Cl}^{-}}\right) C_{\mathrm{NaCl}}+\sigma_{\mathrm{H}_{2} \mathrm{O}}$

where $\lambda_{\mathrm{Na}+}$ and $\lambda_{\mathrm{Cl}-}\left(\mathrm{S} . \mathrm{m}^{2} . \mathrm{mol}^{-1}\right)$ are the molar ionic conductivity of $\mathrm{Na}^{+}$and $\mathrm{Cl}^{-}$ions, respectively, $C_{\mathrm{NaCl}}$

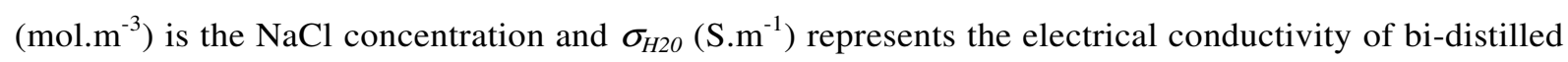
water $\left(3 \times 10^{-6} \mathrm{~S} \cdot \mathrm{m}^{-1}\right)$.

At the vicinity of the PET/microchannel interface, ions with opposite charges are attracted by a migration phenomenon according to the microelectrode polarity. Therefore, an electrical double layer (EDL) appears at the PET interface composed by a compact layer (stern layer) and a diffuse layer 
(Gouy-Chapman) which thickness is closely related to the Debye length, $\lambda_{\mathrm{D}}$, that depends on the ionic strength, here sodium chloride concentration in the microchannel solution.

The Debye length is expressed as follows,

$$
\lambda_{D}=\sqrt{\frac{\varepsilon_{0} \varepsilon_{r} k_{B} T}{2 N_{A} e^{2} C_{\mathrm{NaCl}}}}
$$

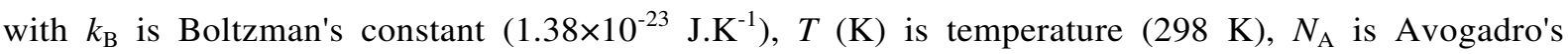
number $\left(6.023 \times 10^{23} \mathrm{~mol}^{-1}\right)$, and $e$ is the elementary charge $\left(1.602 \times 10^{-19} \mathrm{C}\right)$.

For the interface constituted to the PET in contact with the electrolyte, the relative permittivity is assumed to be equal to the microchannel permittivity i.e. $\varepsilon_{r, \text { interface }}=\varepsilon_{r, \text { microchannel }}$.

Moreover, the PET/ electrolyte interface behaves as a capacitor and the interfacial impedance of PET/microchannel interface named $\left(Z_{\text {int }}(\omega)\right)$ can be expressed as follows,

$$
Z_{\text {int }}(\omega)=\frac{1}{j \omega C_{i n}}
$$

Taking into account a length about of $3 \lambda_{\mathrm{D}}$ according to the Debye-Huckel approximation, the capacity at the interface can be found as follows,

$$
C_{\text {int }}=\frac{\mathcal{E}_{0} \varepsilon_{r, \text { int erface }}}{3 \lambda_{D}}
$$

\subsection{Meshing of PET chip geometry}

The accuracy of simulation depends on the mesh quality, namely the number of meshes at the various interfaces. As shown in Fig. 3, free triangular and tetrahedral meshes were used in 3-D, for which the mesh parameters are reported in Table 1. The whole 3-D geometry of microchip is $3.5 \mathrm{~cm} \mathrm{x} 3.5 \mathrm{~cm} \mathrm{x}$ $170 \mu \mathrm{m}$. For more details about the mesh test convergence see Fig. S1 in the supporting information.

Fig. 3

\section{Table 1}

\subsection{Modelling results}

In a previous study,[21] two main difficulties were encountered using electrical equivalent circuits for describing the contactless microelectrodes inside microchip. First, the difficulty was to correctly represent a rough interface PET/ microchannel. Indeed, the laser photoablation process generates a high 
roughness at the PET surface.[18],[28] For this purpose, the constant phase element (CPE) was used to represent the surface heterogeneities in the $R C$ time distribution at the PET interface.

$Z_{\text {int }}(\omega)=\frac{1}{(j \omega)^{\alpha_{\text {int }}} Q_{\text {int }}}$

where $\alpha_{\text {int }}$ is the CPE exponent.

The experimental value of the CPE exponent was 0.5, in a good agreement with the De Levie model [29] accounting for the impedance of a rough surface. However, in the present work, we cannot investigate the surface roughness in our calculation due to the difficulty to integrate the photoablated surface geometry with the finite elements approach and to discretize it. As a consequence, we only considered a smooth surface $\left(\alpha_{\text {int }}=1\right)$ due to a lack of information about the photoablated PET surface. It can be assumed that in the case of a smooth PET surface where the influence of its roughness is negligible, the interfacial impedance exponent tends to 1 , and the results that will be obtained with the use of finite element should be closely similar to those obtained with electrical equivalent circuits approach.

The second difficulty was to separate the impedance contribution of the $5 \mu \mathrm{m}$-PET contactless layer from global impedance because it was in series association with the interfacial impedance and the impedance of the PET filled microchannel, as expressed in Eq. (2). Finally, a procedure to eliminate $Z_{2}(\omega)$ contribution frequency by frequency has permitted a direct observation of the properties of the electrolyte flowing in the microchannel. The same strategy was used for impedances modelling with finite elements approach. Indeed, the calculation procedure steps were carried out within two configurations of the microchip in 3-D. First, the whole geometry of microchip (Fig. 2A) was represented in 3-D to estimate the impedance $Z_{2}(\omega)$ when the channel was empty. Second, the bottom layer of the microchip was suppressed (i.e. the 120- $\mu$ m PET layer) as depicted Fig. 2B. Consequently, only the upper layer of the microchip was considered i.e. the top surface of the two planar microelectrodes, the 5- $\mu \mathrm{m}$ PET layer and the PET microchannel filled with the electrolyte. This configuration was useful for modelling the impedance $Z_{1}(\omega)$ in 3-D, as depicted in Fig. 4.

Fig. 4

\subsubsection{Electric current density calculations}

In the case of the entire geometry of the microchip (Fig. 2A) with a microchannel filled with a $5 \times 10^{-4} \mathrm{M}$ $\mathrm{NaCl}$ solution, the current density was calculated for several frequencies $(1 \mathrm{MHz}, 100 \mathrm{kHz}, 1 \mathrm{kHz}$ and 1 $\mathrm{Hz})$ as showed in Fig. 5. The higher current density $\left(18 \mathrm{~A}^{-2} \mathrm{~m}^{-2}\right)$ is obtained through the PET device at 1 
$\mathrm{MHz}$ (Fig. 5A). The current decreases with the frequency, and at $1 \mathrm{~Hz}$, the lower current density $\left(4.7 \times 10^{-5} \mathrm{~A} \cdot \mathrm{m}^{-2}\right)$ is obtained, as shown in Fig. 5D. This indicates that the capacitive behavior of the system corresponding to the coupling effect between the microelectrodes dominates the impedance response in the HF. This result is in agreement with our previous observations [21] and gives evidence that the capacitive coupling effect has to be taken into account for data interpretation in the non-contact PET device.

The numerical simulation results of the electrical current calculated at different fixed frequencies (1 $\mathrm{MHz}, 1 \mathrm{~Hz}$ ) when only a part of the device geometry is considered for the determination of the impedance $Z_{1}(\omega)$ are presented in Fig. 6 for a $5 \times 10^{-4} \mathrm{M} \mathrm{NaCl}$ solution filling the PET microchannel. It is clearly shown that the same trend for the current is obtained in the whole frequency range when the comparison is done between the two geometry. However, a significant increase is recorded for the electrical current density values with the restricted geometry. For instance, at $1 \mathrm{MHz}$, the current density reached 27 A.m ${ }^{-2}$ for the configuration presented in Fig. 2a, while it was only 18 A.m ${ }^{-2}$ for the configuration presented in Fig. 2 b.

Fig. 5

Fig. 6

\subsubsection{Non-Faradic electric impedance calculations}

The simulated impedances $Z_{\mathrm{G}}(\omega), Z_{1}(\omega)$ and $Z_{2}(\omega)$ are presented in Fig. 7. In the Nyquist representation, a semicircle is observed in the high frequency domain, which can be ascribed to the microchannel conductivity since $Z_{G}(\omega)$ and $Z_{2}(\omega)$ correspond to the filled microchannel and the empty microchannel, respectively. In other words, the only difference between these two calculations is that the conductivity in the case of $Z_{\mathrm{G}}(\omega)$ is different from zero $\left(0.01 \mathrm{~S} . \mathrm{m}^{-1}\right)$ unlike $Z_{2}(\omega)$. In addition, a well-defined semicircle is observed on Fig. 7a (insert) for $Z_{1}(\omega)$ when compared to $Z_{G}(\omega)$. In the low frequency domain, a capacitive branch is obtained in both cases, as previously observed on experimental results.[21] The pure capacitive behavior corresponds to the case when the dielectric polymer acts as an ideal capacitor. In the case of a laser photoablation process, the surface roughness may lead to surface impedance contribution, i.e. a CPE behavior. However, it should be mentioned that such a behavior does not change, in the following, the physical interpretation of the impedance data.

An increase of the real part of impedance, $Z^{\prime}{ }_{1}(\omega)$ is also observed. This effect is even more pronounced than the real part, $Z_{\mathrm{G}}{ }^{\prime}(\omega)$, (Fig. $7 \mathrm{~b}$ ), and is attributed to the parallel contribution of the impedance corresponding to the $120 \mu \mathrm{m}$-PET layer between microelectrodes (Eq. 2).

Moreover, it can be shown on Figure 7c for frequencies higher than $100 \mathrm{kHz}$, that the imaginary part $Z_{1}{ }^{\prime}(\omega)$ is larger than $Z_{\mathrm{G}}{ }^{\prime}(\omega)$, thus indicating a decrease of the capacitance. This is due to the truncated geometry (Fig. 2b) used for eliminating the capacitance of the $120 \mu \mathrm{m}$-PET layer between the microelectrodes. These results underline that procedure which consists in eliminating $Z_{2}(\omega)$ contribution 
from the global impedance $Z_{\mathrm{G}}(\omega)$, permits a better observation of the capacitive coupling effect between the $5 \mu \mathrm{m}$-PET layer capacitance and the interfacial capacitance associated in series, as also shown in the expression of the impedance $Z_{1}(\omega)$ given by the Eq. 2 .

\section{Fig. 7}

The impedance $Z_{1}(\omega)$ for various solution conductivities (twice-distilled water and diluted $\mathrm{NaCl}$ ) are presented in Fig. 8. In the high frequency domain, a semicircle with a diameter corresponding to the microchannel resistance, $R_{\text {S.modeling }}$, is obtained in the Nyquist plot. The largest loop diameter is obtained for the lower conductivity (i.e. twice-distilled water). In addition, the loop diameter varies with the inverse of the conductivity.

In the intermediate frequency domain, a plateau appears for which the values of real part, $Z_{1}{ }^{\prime}(\omega)$, is frequency independent (Fig. 8b). It can be also noted that the plateau value depends to microchannel conductivity. For instance, a plateau value is found from $1 \mathrm{kHz}$ to $10 \mathrm{kHz}$ for a $10^{-5} \mathrm{M} \mathrm{NaCl}$ concentration $\left(\sigma_{\mathrm{NaCl}}\left(10^{-5} \mathrm{M}\right)=1 \mathrm{~S} . \mathrm{m}^{-1}\right)$ and from $1 \mathrm{kHz}$ to $100 \mathrm{kHz}$ for a $5 \times 10^{-4} \mathrm{M} \mathrm{NaCl}$ concentration $\left(\sigma_{\text {NaCl }}\left(5 \times 10^{-4} \mathrm{M}\right)=500 \mathrm{~S} . \mathrm{m}^{-1}\right)$. This indicates that the microchannel resistance can be determined accurately by selecting the correct frequency range as a function of the electrolyte conductivity. In other words, as shown in Fig. 8b, a cut-off frequency shift depending on the microchannel electrical conductivity is observed. For instance, a tenfold increase of the cut-off frequency is observed when the microchannel conductivity increases in the same proportion (from $3 \mathrm{kHz}$ for $10^{-5} \mathrm{M} \mathrm{NaCl}$ and from 30 $\mathrm{kHz}$ for $\left.10^{-4} \mathrm{M} \mathrm{NaCl}\right)$.

In the low frequency range (Fig. 8c), the imaginary part of $Z_{1}$ is independent of the frequency for $f<100 \mathrm{~Hz}$. This indicates the predominance of the $5 \mu \mathrm{m}$-PET layer capacitance, while, as mentioned above, the capacitive coupling effect between $C_{5 \mu \mathrm{m} \text {-PET }}$ and $C_{\mathrm{int}}$ appears for higher frequency, only. The cut-off frequency is also shifted with the increase of the solution conductivity. As a consequence, the interfacial capacitance variations combined with a low insulating layer capacitance can be determined as a function of the solution resistivity in the device as presented in Table 2. Obviously, $C_{\text {int }}$ varies with the inverse of the Debye layer thickness while a linear variation between the solution resistivity and the microchannel resistance is obtained. The same observation was performed on the experimental data with a CPE element for describing the interfacial impedance [21].

Fig. 8

\section{Table 2}

It is noteworthy that both experimental and modeling values of loop diameters are very close. For instance, in the case of twice-distilled water, the electrical conductivity $\sigma_{\text {H2O.exp }}=3 \mu \mathrm{S} . \mathrm{cm}^{-1}$ used in previous experiment led to

$R_{\text {S.exp }}=4.5 \times 10^{8} \Omega$ [21] and the modeling result leads to $R_{\text {S.modeling }}=5 \times 10^{8} \Omega$. As observed in Fig. 9 in the case of solution resistivity of $3 \mu \mathrm{S} . \mathrm{cm}^{-1}$, a good agreement between experiment and modelled impedances was obtained. However, some discrepancies between experimental and modelled values were observed in the high frequencies 
for the real parts of impedance, and in the low frequencies for the imaginary parts. Thereby, at high frequencies, origin of the difference is mainly due to the description of the PET/microchannel interface by a pure capacitor $(\alpha=1)$. As mentioned above, the photoablated PET interface should be considered as a CPE behavior with $\alpha$ exponent equal to 0.5 . The contribution of both the real and imaginary parts of the impedance of the CPE to the global impedance of the microdevice is important in the whole frequency range (1 MHz to $1 \mathrm{~Hz})$. However, the intermediate frequency range provides a domain (3 to 4 decades of frequencies) on which data analysis allowed to investigate the solution properties inside the microchannel. In fact, the gap at high frequencies is due to the lack of resistive part at the modeled interface. Similarly, the difference at low frequencies is due to presence of only the capacitive effect in the model.

Fig. 9

The plot of the loop diameter variation as a function of microchannel electrical resistivity (Fig. 10) shows a straight line passing through the origin. The value of the slope obtained from the fit of the experimental data corresponds to the microchannel cell constant and is equal to $8 \times 10^{4} \mathrm{~m}^{-1}$. The modeling cell constant is slightly lower than the experimental one previously determined $\left(5 \times 10^{3} \mathrm{~m}^{-1}\right)$ [25]. The discrepancy between the experimental and modelled apparent cell-constant originates from the resistive contribution of the photoablated PET surface, which has been neglected in our simulations. Indeed, this contribution also contains roughness of the photoablated surface that cannot be taken into account in FEM simulations.

Fig. 10

\subsubsection{Methodology for non-contact microchannel resistance prediction in a selected frequency range}

As mentioned in the introduction, a plethora of application fields requires the determination of microchannel resistance. Therfore, il is important to developed an analytical expression for impedance of microchannel for predicting within which frequency range or at which fixed frequency the microchannel resistance can be accurately monitored.

The impedance of the $5 \mu \mathrm{m}$ thick PET layer was expressed as a capacitor. Additionally, the PET/microchannel interface also behaves as an ideal capacitor $\left(C_{i n t}\right)$ when a smooth surface is considered, which is often the case for PDMS/ glass system. In the microchannel, impedance is represented by an $R_{\mathrm{S}} / / C_{\mathrm{S}}$ circuit, in which $R_{\mathrm{S}}$ is the characteristic resistance of the microchannel and $C_{\mathrm{S}}$ the cell capacitance. This latter is observed in very high frequencies in dielectric media.

Additionally, the impedance $Z_{l}$ can be expressed as follows: 
$Z_{1}(\omega)=-\frac{j}{\omega C_{P E T}}-\frac{j}{\omega C_{\mathrm{int}}}-\frac{j \omega C_{S} R_{S}{ }^{2}}{1+\omega^{2} C_{S}{ }^{2} R_{S}{ }^{2}}+\frac{R_{S}}{1+\omega^{2} C_{S}{ }^{2} R_{S}{ }^{2}}$

After development, we obtain the following expression of the impedance $Z_{1}(\omega)$ for which the real part $Z^{\prime}{ }_{1}(\omega)$ and the imaginary part $Z{ }^{\prime}{ }_{1}(\omega)$ can be clearly identified.

$Z_{1}(\omega)=\frac{R_{S}}{1+\omega^{2} C_{S}{ }^{2} R_{S}{ }^{2}}-j\left[\frac{1}{\omega C_{P E T}}+\frac{1}{\omega C_{\mathrm{int}}}+\frac{\omega C_{S} R_{S}{ }^{2}}{1+\omega^{2} C_{S}{ }^{2} R_{S}{ }^{2}}\right]$

with

$Z_{1}^{\prime}(\omega)=\frac{R_{S}}{1+\omega^{2} C_{S}{ }^{2} R_{S}{ }^{2}}$

and

$-Z_{1}^{\prime \prime}(\omega)=\frac{1}{\omega C_{P E T}}+\frac{1}{\omega C_{\mathrm{int}}}+\frac{\omega C_{S} R_{S}^{2}}{1+\omega^{2} C_{S}^{2} R_{S}^{2}}$

The targeted application is the real-time monitoring of the microchannel resistance. Thus, only the real part of the impedance which contains the contribution of the resistance is of interest for this application.

Eq. 15 allows to express $R_{\mathrm{S}}$ as a polynomial function which is independent of the impedance of the $5 \mu \mathrm{m}-$ PET layer:

$\omega^{2} C_{S}^{2} Z_{1}^{\prime}(\omega) R_{S}^{2}-R_{S}+Z_{1}^{\prime}(\omega)=0$

The numerical values of $C_{S}=9 \times 10^{-14}(\mathrm{~F})$ is obtained from the imaginary equation of $Z_{l}(\omega)$ using Eq. (16) at a low electrolyte concentration (high $R_{S}$ value in Nyquist diagram). The solution of the Eq. (17) thus leads to the expression of the microchannel resistance as follows,

$R_{S}=\frac{1+\sqrt{1-4 \omega^{2} C_{S}^{2}\left(Z_{1}^{\prime}(\omega)\right)^{2}}}{2 \omega^{2} C_{S}^{2} Z_{1}^{\prime}(\omega)}$

The frequency to be used for the real-time monitoring of the microchannel resistance has to be selected in the frequency window where the $R_{S}$ value is directly measurable i.e. is frequency independent as exemplified in Fig. 11 (see the plateaus on the $R_{S}$ vs $f$ plots).

Fig. 11

Eq. (18), takes advantage of predicting the contactless microchannel resistance. As shown in Fig. 8b, the contactless device behaves as a capacitive system for which the EDL developed must be as large as possible (low ionic concentration) in order to decrease the fixed frequency to be selected and gained 
confidence in the sensitivity. By using Eq. (18) with the experimental real part of impedance values and also $C_{S}, R_{S}$ can be plotted as a function of the frequency as it shown in Fig. 12. Two limit cases were considered to highlight that the validity domain of $R_{S}$ parameter is larger in case of water than for $10^{-2} \mathrm{M}$ $\mathrm{NaCl}$. These results indicate that the evaluation of solution resistivity at fixed frequency for solution having a high ionic strength is more difficult and it should be investigated at very high frequencies (the plateau shifts outside of the conventional range of EIS investigation). Thereby, experimental value of $R_{S}$ (loop diameter of Nyquist plot) is found close to the estimated value by $R_{S}$. However, this observation means that microchannel resistance in the case of low ionic strength should be easily measured for online monitoring at fixed frequency.

Fig. 12

It should also be emphasized that this procedure checking is crucial to be certain that changes in the microchannel resistance are only ascribable to a chemical reaction taking place. Alternatively, the monitoring of the real part variation against time at a given frequency can be used to deduce the microchannel resistance $R_{\mathrm{S}}$ (or conductance, $\mathrm{G}$ ) as shown by the Eq. (15).

\section{Conclusion}

In this study, non-faradic electric impedance spectroscopy through electrically insulated microelectrodes in flexible polymer was modelled using finite element method. The modelled impedance in the case of an empty microchannel and by varying the conductivity allowed a better understanding of the distribution of electrical streamlines in the whole microdevice. Indeed, in the high frequency range a capacitive coupling effect takes place from each side of the dielectric polymer isolating the microelectrodes. On the one hand, the ionic charges adsorb at the PET / streaming electrolyte interface and on the other hand, the electric charges accumulate at the microelectrodes / PET interface. Moreover, a relationship between loop diameter of time constant shown in the Nyquist diagram as a function of the electrical conductivity of the streaming electrolyte permits a non-contact cell constant determination. In addition, the frequency to use for real-time monitoring of the contactless microchannel can be accurately predicted.

\section{Acknowledgements}

The authors would like to thank the French institute for research and Development (IRD, France) and Sorbonne Universités (UPMC, France) for the co-funding doctoral program, and the University of Bejaia (Algeria) for its financial support. 


\section{References}

[1] Z. Walsh, M. Vazquez, F. Benito-Lopez, B. Paull, M. Macka, F. Svec, D. Diamond, The use of scanning contactless conductivity detection for the characterisation of stationary phases in micro-fluidic chips, Lab on a Chip, 10 (2010) 1777 1780.

[2] D. Sun, J. Lu, Z. Chen, Microfluidic contactless conductivity cytometer for electrical cell sensing and counting, RSC Advances, 5 (2015) 59306-59313.

[3] M.B. Sano, J.L. Caldwell, R.V. Davalos, Modeling and development of a low frequency contactless dielectrophoresis (cDEP) platform to sort cancer cells from dilute whole blood samples, Biosensors and Bioelectronics, 30 (2011) 13-20.

[4] F.S.O. Fritzsch, K. Rosenthal, A. Kampert, S. Howitz, C. Dusny, L.M. Blank, A. Schmid, Picoliter nDEP traps enable timeresolved contactless single bacterial cell analysis in controlled microenvironments, Lab on a Chip, 13 (2013) 397-408.

[5] S. Emaminejad, R.W. Dutton, R.W. Davis, M. Javanmard, Multiplexed actuation using ultra dielectrophoresis for proteomics applications: a comprehensive electrical and electrothermal design methodology, Lab on a Chip, 14 (2014) 2105-2114.

[6] C.-C. Chen, P.-H. Lin, C.-K. Chung, Microfluidic chip for plasma separation from undiluted human whole blood samples using low voltage contactless dielectrophoresis and capillary force, Lab on a Chip, 14 (2014) 1996-2001.

[7] M. Gao, L. Gui, A handy liquid metal based electroosmotic flow pump, Lab on a Chip, 14 (2014) 1866-1872.

[8] X. Fu, N. Mavrogiannis, S. Doria, Z. Gagnon, Microfluidic pumping, routing and metering by contactless metal-based electro-osmosis, Lab on a Chip, 15 (2015) 3600-3608.

[9] S.H. Tan, B. Semin, J.-C. Baret, Microfluidic flow-focusing in ac electric fields, Lab on a Chip, 14 (2014) 1099-1106.

[10] K. Park, H.-J. Suk, D. Akin, R. Bashir, Dielectrophoresis-based cell manipulation using electrodes on a reusable printed circuit board, Lab on a Chip, 9 (2009) 2224-2229.

[11] S. Emaminejad, M. Javanmard, R.W. Dutton, R.W. Davis, Microfluidic diagnostic tool for the developing world: contactless impedance flow cytometry, Lab on a Chip, 12 (2012) 4499-4507.

[12] J. Freudenberg, S. Schelle, K. Beck, M. von Schickfus, S. Hunklinger, A contactless surface acoustic wave biosensor, Biosensors and Bioelectronics, 14 (1999) 423-425.

[13] X. Fang, H. Zhang, F. Zhang, F. Jing, H. Mao, Q. Jin, J. Zhao, Real-time monitoring of strand-displacement DNA amplification by a contactless electrochemical microsystem using interdigitated electrodes, Lab on a Chip, 12 (2012) 31903196.

[14] X. Fang, Q. Jin, F. Jing, H. Zhang, F. Zhang, H. Mao, B. Xu, J. Zhao, Integrated biochip for label-free and real-time detection of DNA amplification by contactless impedance measurements based on interdigitated electrodes, Biosensors and Bioelectronics, 44 (2013) 241-247.

[15] M. Faure, B. Sotta, J. Gamby, Investigating the kinetics of paramagnetic-beads linked alkaline phosphatase enzyme through microchannel resistance measurement in dielectric microchip, Biosens. Bioelectron., 58 (2014) 61-67.

[16] M. Kechadi, L. Chaal, B. Tribollet, J. Gamby, Dielectric impedance spectroscopy of polymer-coated microelectrodes for adsorption monitoring of proteins within polymer microchannels, Journal of Electroanalytical Chemistry, 737 (2015) 108113.

[17] S.O.P. Blume, R. Ben-Mrad, P.E. Sullivan, Characterization of coplanar electrode structures for microfluidic-based impedance spectroscopy, Sensors and Actuators B: Chemical, 218 (2015) 261-270.

[18] F. Bianchi, Y. Chevolot, H.J. Mathieu, H.H. Girault, Photomodification of Polymer Microchannels Induced by Static and Dynamic Excimer Ablation: Effect on the Electroosmotic Flow, Analytical Chemistry, 73 (2001) 3845-3853.

[19] Z. Wu, H. Jensen, J. Gamby, X. Bai, H.H. Girault, A flexible sample introduction method for polymer microfluidic chips using a push/pull pressure pump, Lab Chip, 4 (2004) 512-515.

[20] R. Truckenmuller, S. Giselbrecht, C. van Blitterswijk, N. Dambrowsky, E. Gottwald, T. Mappes, A. Rolletschek, V. Saile, C. Trautmann, K.F. Weibezahn, A. Welle, Flexible fluidic microchips based on thermoformed and locally modified thin polymer films, Lab on a Chip, 8 (2008) 1570-1579.

[21] M. Kechadi, J. Gamby, L. Chaal, H. Girault, B. Saidani, B. Tribollet, Polymer microchip impedance spectroscopy through two parallel planar embedded microelectrodes: Understanding the impedance contribution of the surrounding polymer on the measurement accuracy, Electrochim. Acta, 105 (2013) 7-14.

[22] M. Faure, M. Kechadi, B. Sotta, J. Gamby, B. Tribollet, Contact Free Impedance Methodology for Investigating Enzymatic Reactions into Dielectric Polymer Microchip, Electroanalysis, 25 (2013) 1151-1158.

[23] M. Kechadi, L. Chaal, B. Tribollet, J. Gamby, Dynamics of BSA adsorption onto a photoablated polymer surface in a dielectric microchip, Analyst (Cambridge, U. K.), 139 (2014) 1492-1497.

[24] M. Kechadi, B. Sotta, L. Chaal, B. Tribollet, J. Gamby, A real time affinity biosensor on an insulated polymer using electric impedance spectroscopy in dielectric microchips, Analyst (Cambridge, U. K.), 139 (2014) 3115-3121.

[25] M. Kechadi, B. Sotta, J. Gamby, Microchannel conductivity measurements in microchip for on line monitoring of dephosphorylation rates of organic phosphates using paramagnetic-beads linked alkaline phosphatase, Talanta, 132 (2015) 785-789.

[26] M. Kechadi, J. Gamby, L. Chaal, B. Saidani, B. Tribollet, Free Contact Microchannel Impedance Through Two Antiparallel Planar Microelectrodes, Journal of Flow Chemistry, 3 (2013) 81-86. 
[27] M. Kechadi, L. Chaal, V. Vivier, B. Tribollet, J. Gamby, Electrical impedance spectroscopy of a PET chip sandwiched between two disk electrodes: understanding the contribution of the polymer/electrode interface, Phys. Chem. Chem. Phys., 18 (2016) 20583-20590.

[28] J. Gamby, M. Lazerges, H.H. Girault, C. Deslouis, C. Gabrielli, H. Perrot, B. Tribollet, Electroacoustic Polymer Microchip as an Alternative to Quartz Crystal Microbalance for Biosensor Development, Anal. Chem. (Washington, DC, U. S.), 80 (2008) 8900-8907.

[29] R. De Levie, The influence of surface roughness of solid electrodes on electrochemical measurements, Electrochimica Acta, 10 (1965) 113-130. 


\section{List of tables}

Table 1. Meshing characteristics of microchip in 3-D.

\begin{tabular}{c|c|c} 
meshing characteristics & $\begin{array}{c}\text { Microchannel+ } \\
\text { PET with } 5 \mu \mathrm{m}\end{array}$ & $\begin{array}{c}\text { The rest of the } \\
\text { geometry }\end{array}$ \\
\hline maximum element size & 2 & 15 \\
\hline minimum element size & 0.1 & 1.2 \\
\hline maximum growth rate of element & 1.2 & 0.5 \\
\hline Resolution of the curvature & 0.2 & 0.7
\end{tabular}

Table 2: Modelled values of microchannel resistance " $R_{S}$ " and the interfacial capacitance of PET/microchannel interface " $C_{\text {int }}$ " depending on $\mathrm{NaCl}$ concentrations in the microchannel.

\begin{tabular}{cccc}
\hline $\mathrm{NaCl}(\mathrm{M})$ & $\rho(\Omega . \mathrm{cm})$ & $R_{\text {S.model }}(\Omega)$ & $C_{\text {int }}(\mathrm{F})$ \\
\hline $10^{-5}$ & $57 \times 10^{4}$ & $4.73 \times 10^{8}$ & $6.66 \times 10^{-12}$ \\
\hline $5 \times 10^{-5}$ & $14.6 \times 10^{4}$ & $9.5 \times 10^{7}$ & $2 \times 10^{-11}$ \\
\hline $10^{-4}$ & $77 \times 10^{3}$ & $4.7 \times 10^{7}$ & $3 \times 10^{-11}$ \\
\hline $5 \times 10^{-4}$ & $16 \times 10^{3}$ & $9.7 \times 10^{6}$ & $6.67 \times 10^{-11}$ \\
\hline $10^{-3}$ & $8 \times 10^{3}$ & $4.94 \times 10^{6}$ & $9.67 \times 10^{-11}$ \\
\hline $5 \times 10^{-3}$ & $10^{3}$ & $1.2 \times 10^{6}$ & $2.13 \times 10^{-10}$ \\
\hline $10^{-2}$ & 800 & $9 \times 10^{5}$ & $3.067 \times 10^{-10}$ \\
\hline
\end{tabular}




\section{Figure captions}

Fig. 1. Schematic representation of the contactless device geometry where two planar carbon microelectrodes were electrically insulated in the PET membrane. The superimposed electrical equivalent circuit used for modelling the electric impedance response is composed of two impedances associated in parallel: $Z_{2}$ (in green line) where the current streamlines passing through the two microelectrodes separated by the PET layer $\left(d_{2, \mathrm{PET}}=120 \mu \mathrm{m}\right)$, and $Z$ (in red line) where the current streamlines passing through the microchannel between the two PET layers $\left(d_{1, \mathrm{PET}}=5 \mu \mathrm{m}\right)$ that insulate electrodes i.e. a series association of impedances (see text).

Fig. 2. Sketches of the geometry with boundary and bulk conditions. a. The whole configuration taking into account the $Z_{2}$ impedance contribution. b. The truncated configuration for eliminating the $Z_{2}$ impedance contribution. Microchannel: $\sigma_{\text {microchannel }}=\sum \lambda \mathrm{i} C \mathrm{i}$ and $\varepsilon_{\mathrm{r}, \text { microchannel }}=78, \mathrm{PE}: \sigma_{\mathrm{PE}}=5 \times 10^{-12}\left(\mathrm{~S} \mathrm{~m}^{-1}\right)$ and $\varepsilon_{\mathrm{r}, \mathrm{PE}}=2.9$, PET $: \sigma_{\mathrm{PET}}=3 \times 10^{-12}\left(\mathrm{~S} \mathrm{~m}^{-1}\right)$ and $\varepsilon_{\mathrm{r}, \mathrm{PET}}=3.4$, PET/microelectrode interface: $\sigma(\omega)=3 \times 10^{-11} \omega\left(\mathrm{S} \mathrm{m}^{-1}\right)$, PET/PE interface: $n \mathrm{~J}_{1}=n \mathrm{~J}_{2}$, PET/microchannel interface: $\sigma_{\text {interface }}=3 \times 10^{-11}\left(\mathrm{~S} \mathrm{~m}^{-1}\right), \varepsilon_{\mathrm{r} \text {,inteface }}=78$.

Fig. 3. a. Global view of the obtained meshing on the entire $3-D$ microchip geometry $\left(Z_{\mathrm{G}}(\omega)\right)$ using tetrahedral mesh (See Table 1). b. Magnification of the mesh in the PET thickness of $5 \mu \mathrm{m}$.

Fig. 4. 3- $D$ representation of the $\mathrm{Z}_{1}(\omega)$ contribution of the microchannel impedance.

Fig. 5. Electric current density $\left(A \cdot m^{-2}\right)$ in the global 3-D geometry $(Z G(\omega))$ at different frequencies, the microchannel being filled with $\mathrm{NaCl}$ at $5 \times 10^{-4}$ M. (a) $1 \mathrm{MHz}$. (b) $100 \mathrm{kHz}$. (c) $1 \mathrm{kHz}$. (d) $1 \mathrm{~Hz}$.

Fig. 6. Electric current density $\left(A . m^{-2}\right)$ calculated in 3-D geometry representing $Z_{1}(\omega)$ impedance at two fixed frequencies, the microchannel being filled with $\mathrm{NaCl}$ at $5 \times 10^{-4} \mathrm{M}$. (a) $1 \mathrm{MHz}$. (b) $1 \mathrm{~Hz}$.

Fig. 7. Modelled impedances by the finite elements between $1 \mathrm{MHz}$ to $1 \mathrm{~Hz}$ and at $0.1 \mathrm{~V}$, respectively in the case of microchannel either empty $\left(Z_{2}(\omega)\right)$, or filled with $5 \times 10^{-4} \mathrm{M} \mathrm{NaCl}\left(Z_{\mathrm{G}}(\omega)\right)$ and without the PET $120 \mu \mathrm{m}$ film between the microelectrodes $\left(Z_{1}(\omega)\right)$. (a) Nyquist diagram. (b) Real part vs. frequency. (c) Imaginary part vs. frequency.

Fig. 8. Modelled $Z 1(\omega)$ impedance by the finite element method for various ionic conductivities of the solution, calculated from $1 \mathrm{MHz}$ to $1 \mathrm{~Hz}$ and at $0.1 \mathrm{~V}$. (a) Nyquist diagram. (b) Real part vs. frequency. (c) Imaginary part vs. frequency.

Fig. 9. Experiment and modelled impedances by the finite elements between $1 \mathrm{MHz}$ to $1 \mathrm{~Hz}$ and at $0.1 \mathrm{~V}$, case of electrical conductivity of $3 \mu \mathrm{S} . \mathrm{cm}^{-1}$. (a) Nyquist diagram. (b) Real part vs. frequency. (c) Imaginary part vs. frequency.

Fig. 10. Plot of loop diameter as a function of microchannel electrical resistivity modelled by finite elements. 
Fig. 11. Modelled $R_{\mathrm{S}}(\omega)$ variation with frequency by the finite element at various microchannel ionic conductivities, calculated from $1 \mathrm{MHz}$ to $1 \mathrm{~Hz}$ and at $0.1 \mathrm{~V}$; pure water and seven $\mathrm{NaCl}$ concentrations are shown here: (a) pure water, (b) $10^{-5}$, (c) $5 \times 10^{-5}$, (d) $10^{-4}$, (e) $5 \times 10^{-4}$, (f) $10^{-3}$, (g) $5 \times 10^{-3}$, and (h) $10^{-2} \mathrm{M}$.

Fig. 12. Determination of $R_{\mathrm{S}}$ plateau as confidence intervals (pure water and $10^{-2} \mathrm{M} \mathrm{NaCl}$ ) with frequency calculated using Eq. (18) where the $\operatorname{Re}[\mathrm{Z} 1(\omega)]$ experimental real part (from $1 \mathrm{MHz}$ to $1 \mathrm{~Hz}$ and at $0.1 \mathrm{~V}$ ) and $C_{\mathrm{S}}$ are taken into account. 


\section{List of figures}

Fig. 1

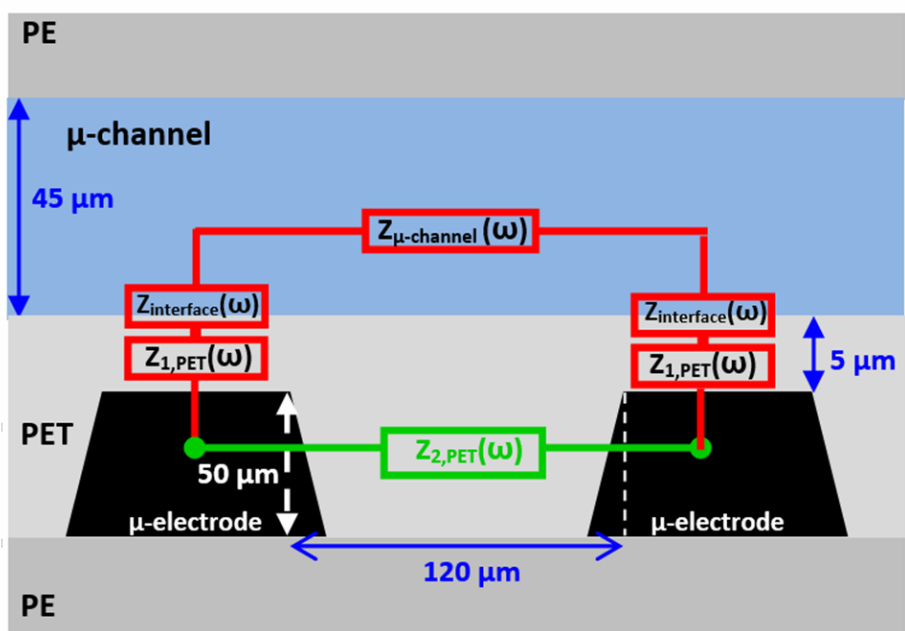


Fig. 2
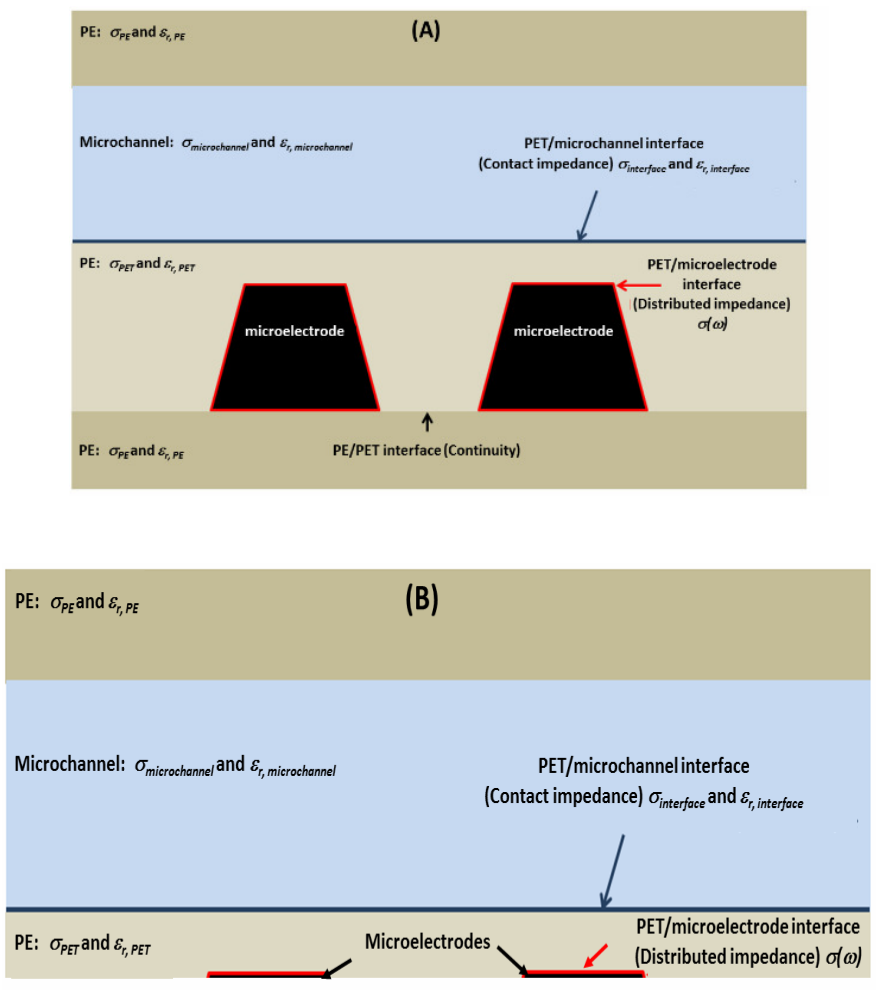
Fig. 3

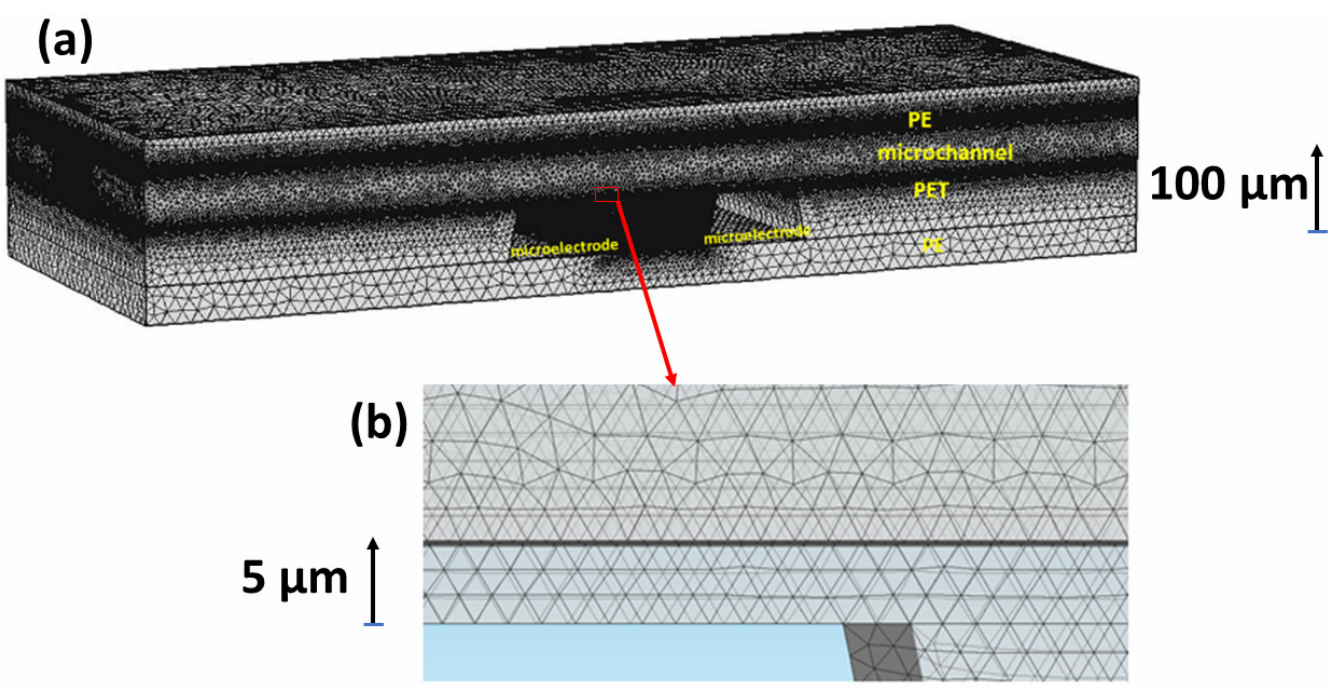


Fig. 4

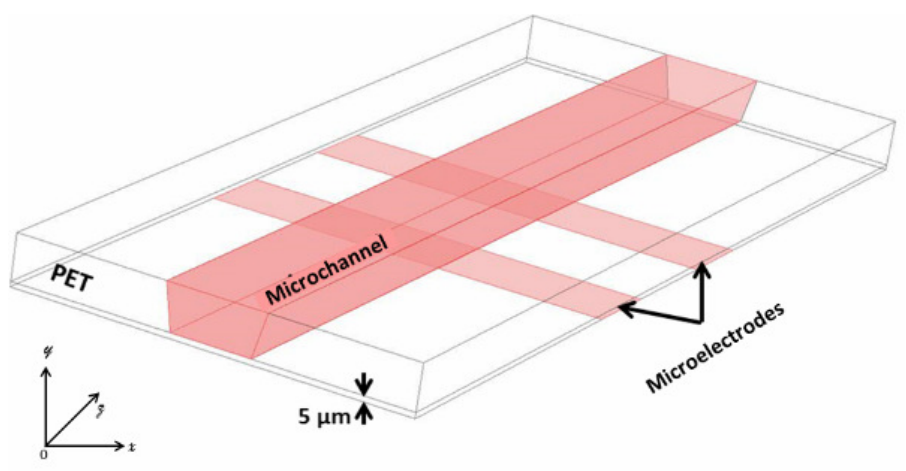


Fig. 5
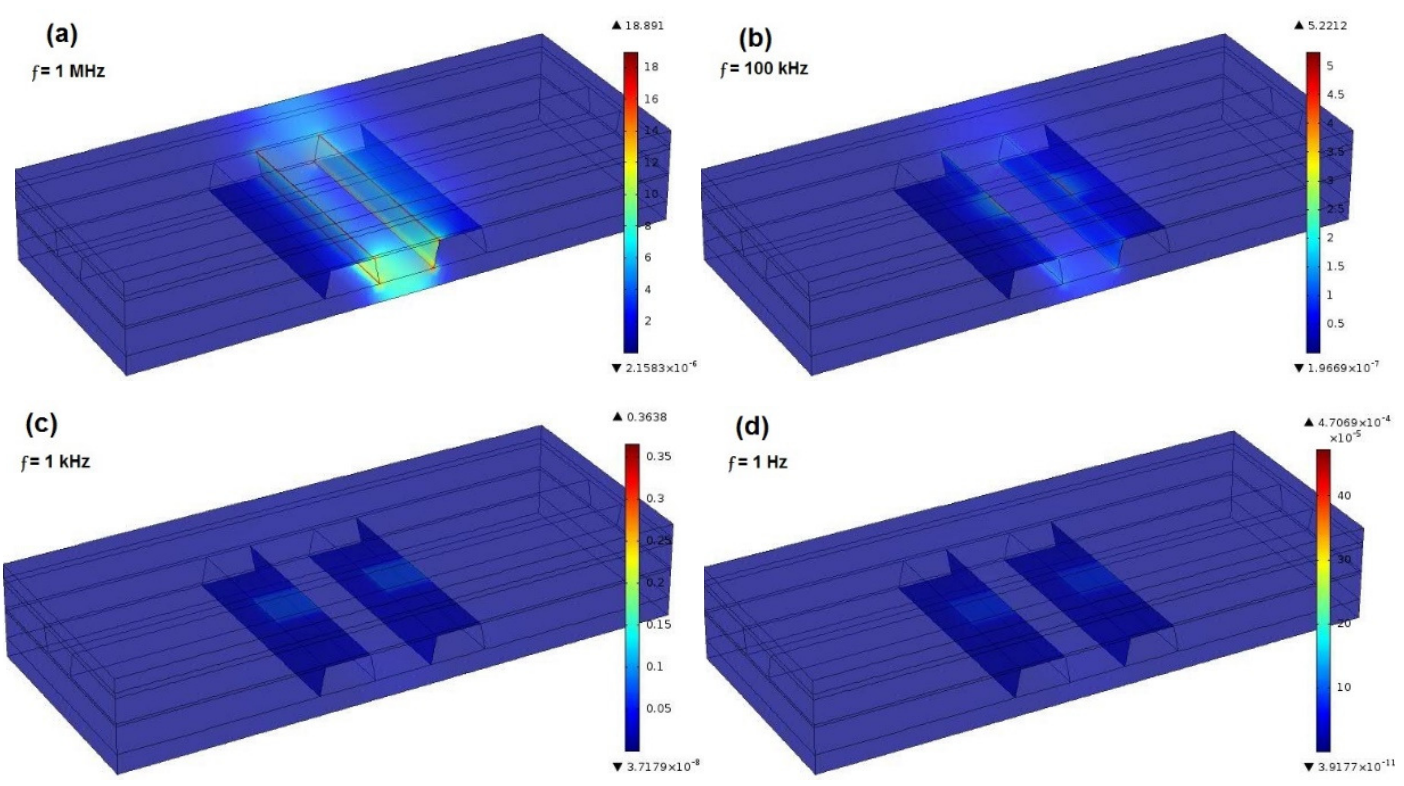

Fig. 7
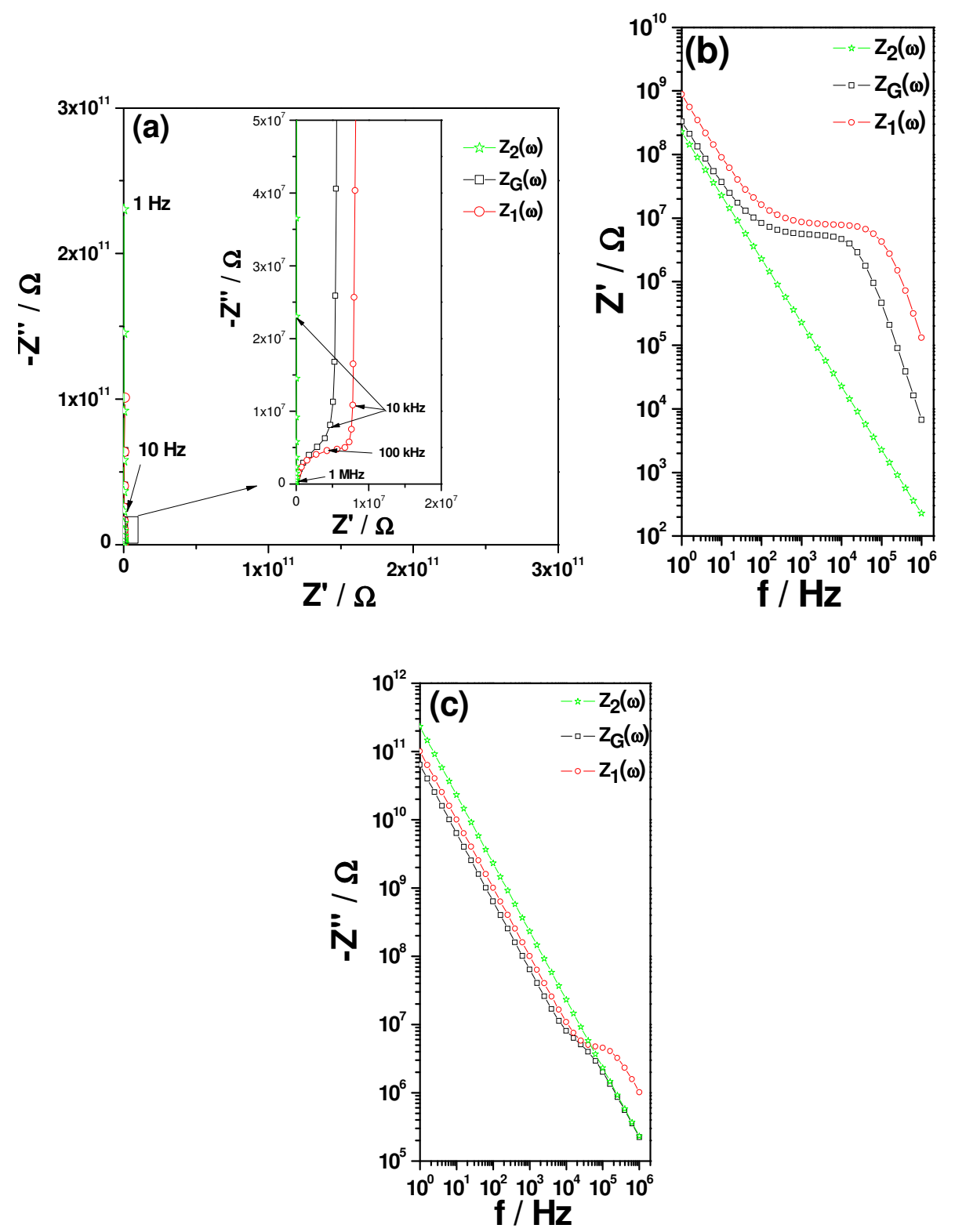
Fig. 8
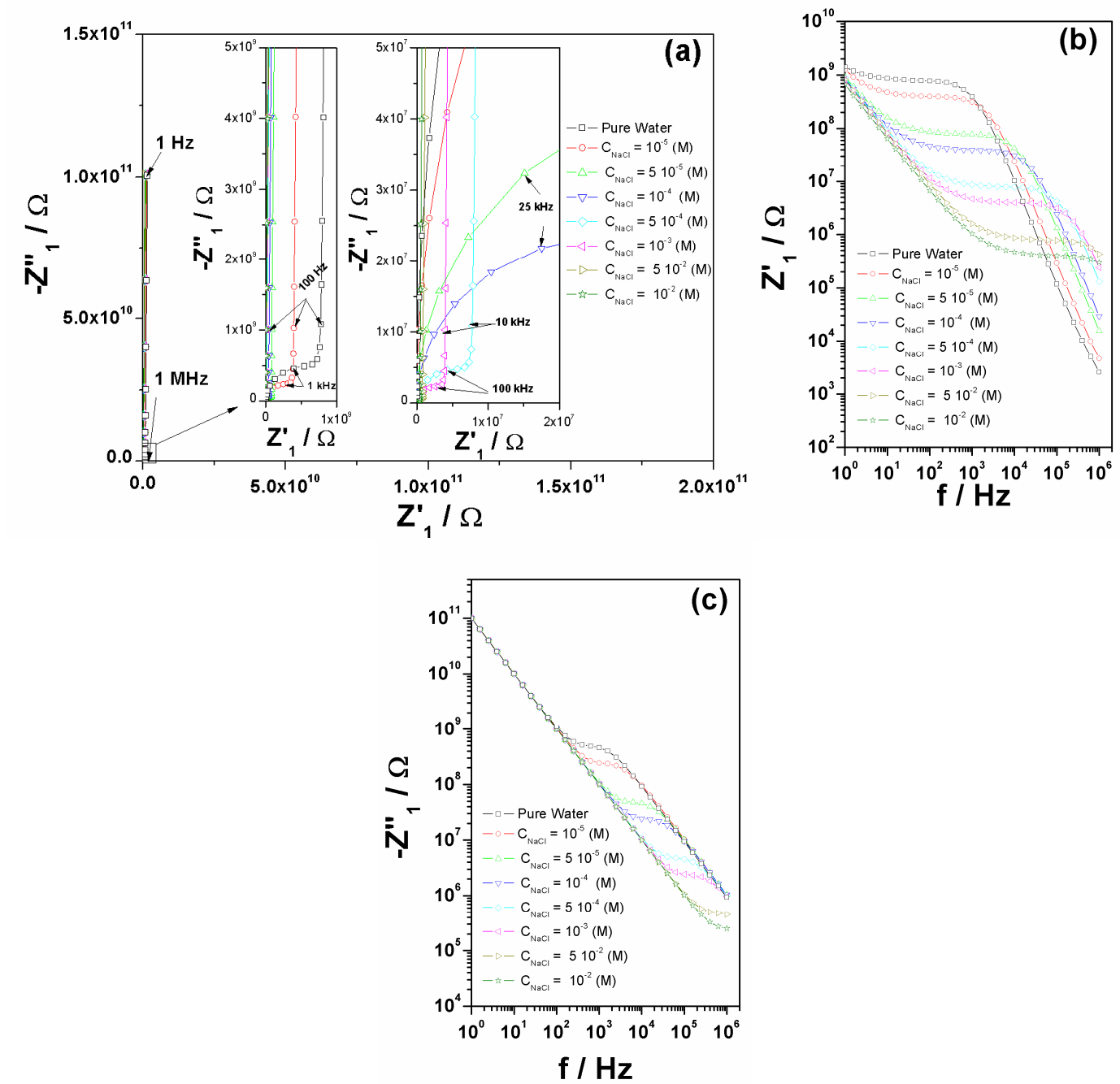
Fig. 9
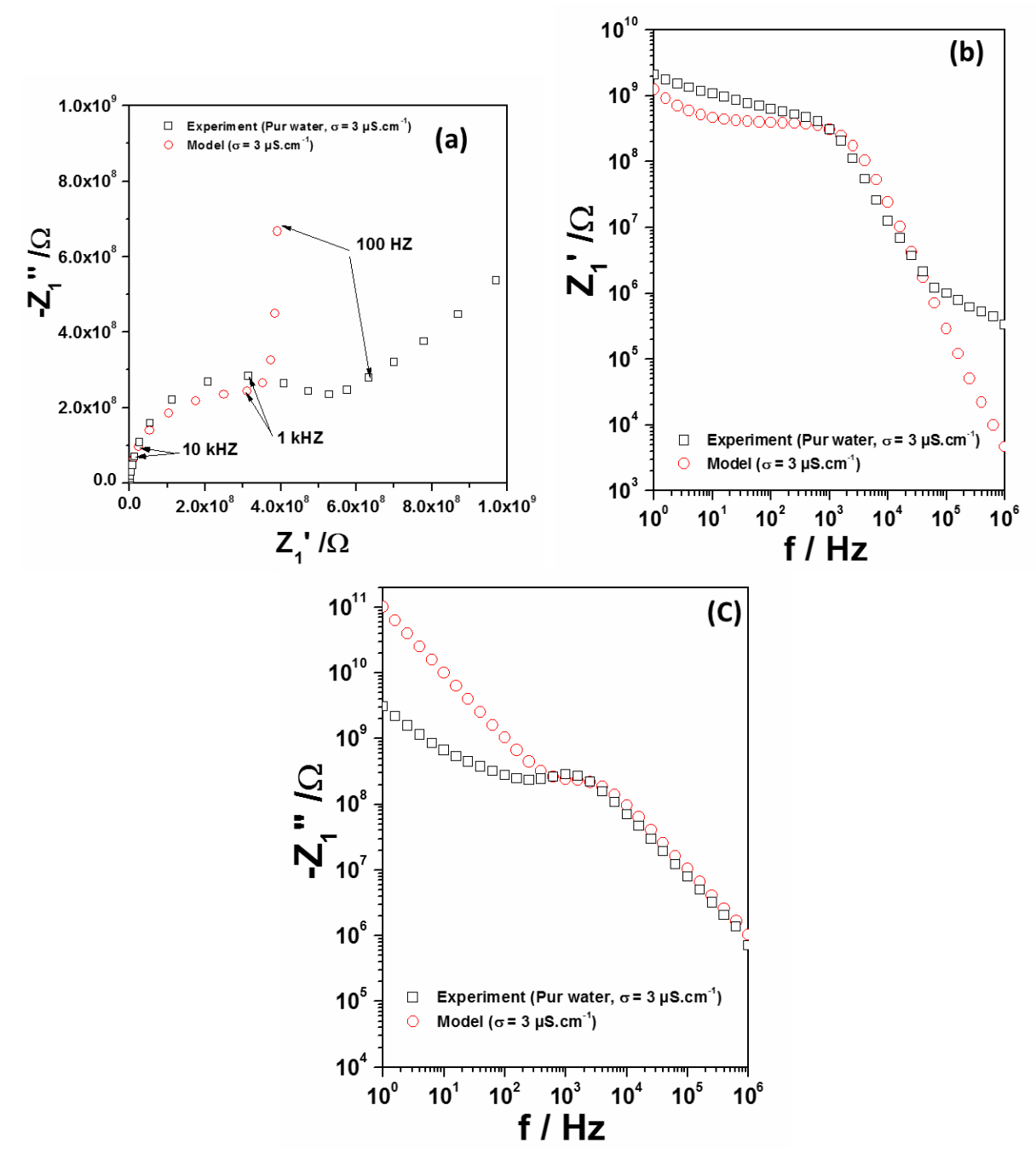
Fig. 10

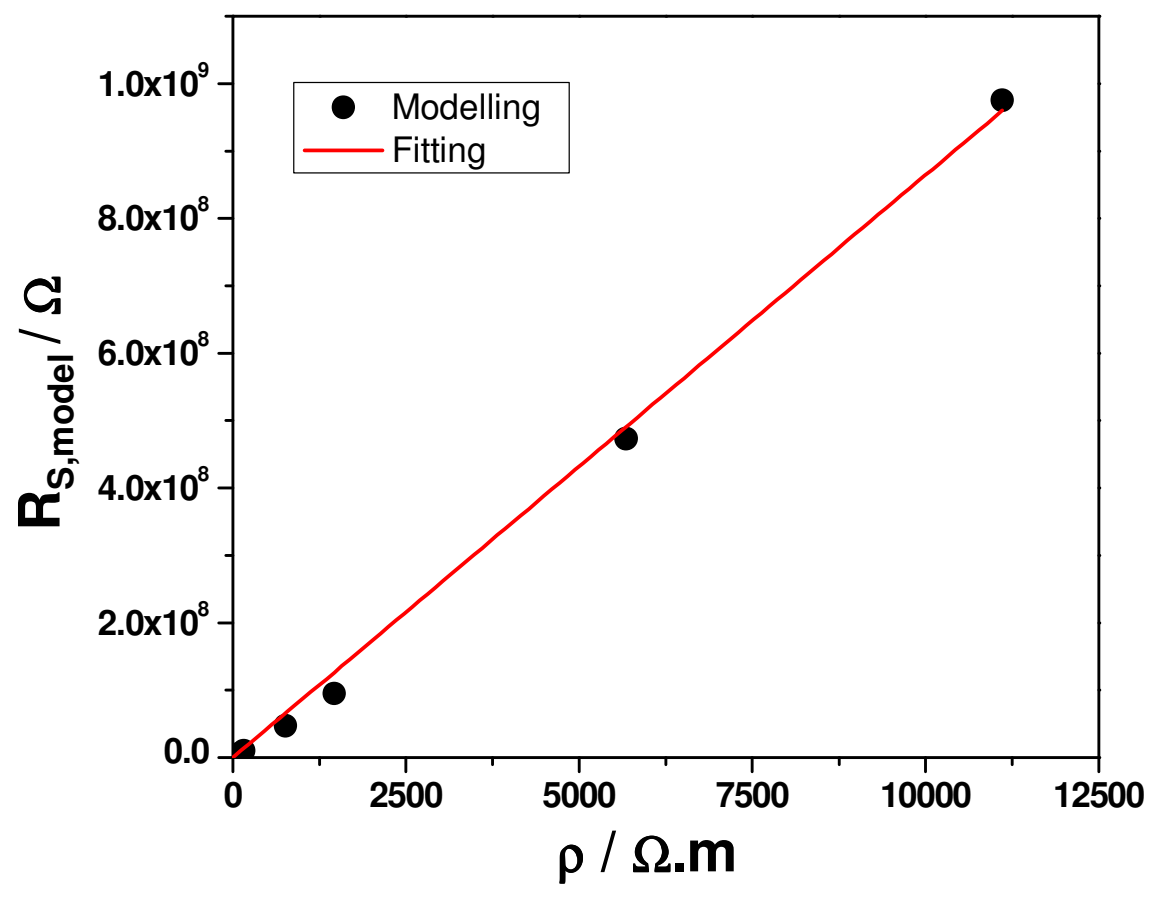


Fig. 11

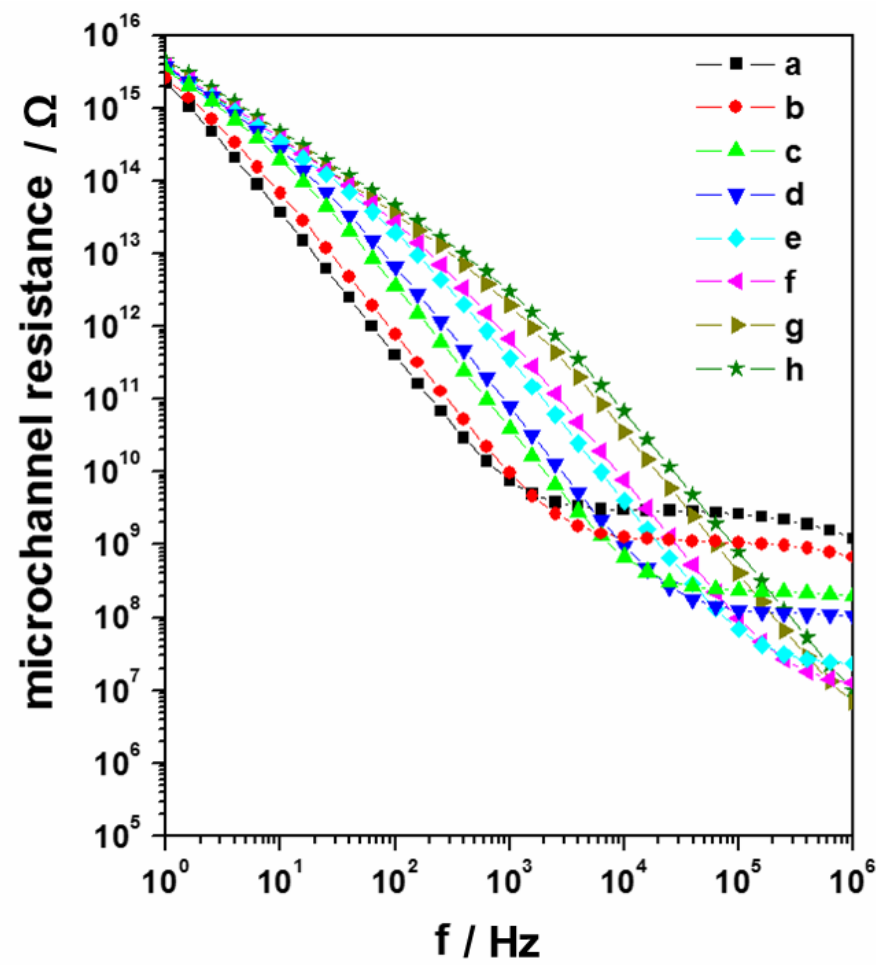


Fig. 12

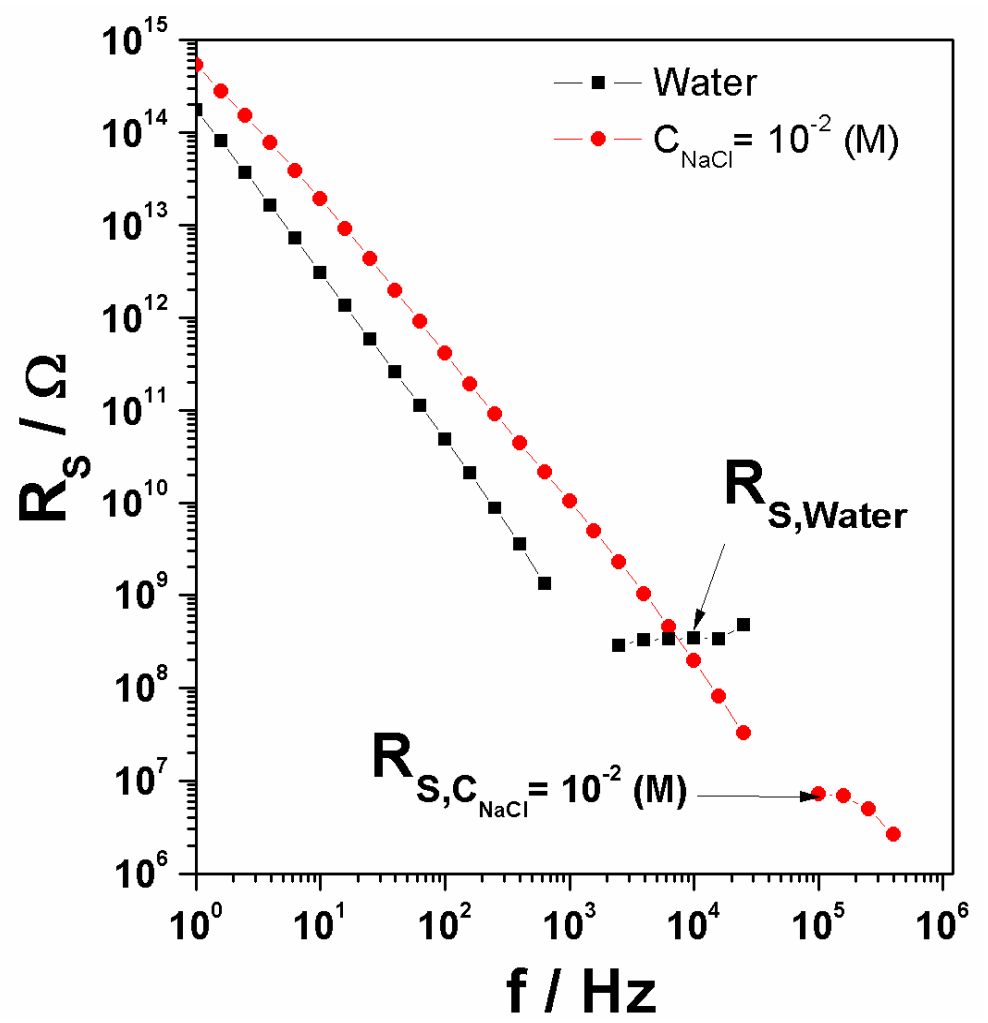

